\author{
Elena DEJU \\ Lycée Magnan, Nisa, France
}

\title{
ASPECTE ALE INFLUENTEI LIMBII FRANCEZE ASUPRA LIMBII ROMÂNE
}

Istoria umanității se identifică cu o luptă continuă pentru asigurarea existenței, în decursul mileniilor, comunitățile omeneşti fiind într-o mişcare permanentă și căutând să-şi satisfacă necesitățile atât prin explorarea, ocuparea şi exploatarea unor noi teritorii, dar şi pe calea contactelor directe sau indirecte, căci încă de la începuturile civilizației omeneşti au avut loc schimburi incidentale de cunoştințe şi bunuri, iar pe măsură ce societatea păşea mai hotărât pe drumul spre civilizație, rolul şi intensitatea schimburilor au crescut vertiginos, iar transformările economice ce au survenit au dus la dezvoltarea economicã, dar și la dinamica lexicului.

În ceea ce privește dinamica lexicului, una dintre limbile care a avut o influențã pregnantã asupra limbii române a fost limba francezã, influența sa fiind strâns legatã de contextul politic, primele cuvinte de origine francezã intrând în limbã încã din secolul al XVIII-lea fie prin intermediul grecilor care au trãit în Moldova și Valahia, fie în momentul apariției emigranților francezi.

In prima jumãtate a secolului al XIX-lea, termenii francezi sunt introduși în limba noastrã, în general, cu ajutorul tinerilor români care își fac studiile la Paris, iar în a doua jumãtate a secolului, aceastã aprigã influențã este ironizatã de cãtre unii scriitori români, printre ei regãsindu-se Mihai Eminescu, Vasile Alecsandri, Ion Luca Caragiale, şi cu toate acestea, românii au continuat sã împrumute termeni francezi și în secolele al XX-lea și al XXI-lea.

Pornind de la aceste aspecte și realizând o comparație între evoluția limbii române şi cea a limbii franceze sesizăm că lexicul românesc evoluează in direcția modernizării şi internaționalizării, atât sub aspectul procedeelor, cât şi al împrumuturilor de afixe [1], iar problemele lingvistice pe care le ridică sunt foarte vaste, una dintre ele fiind cea referitoare la formarea şi evoluția termenilor, sau, aşa cum spunea Marius Sala, certificatul de naştere [2] al cuvintelor.

In timp ce lingviştii asistă la moartea unor cuvinte, altele iau naştere pe de o parte pe cale externă (împrumuturi) şi pe cale internă (derivare, compunere, conversiune), pe de altă parte, datorită calchierii, procedeu 
considerat de unii specialişti mixt sau combinat [3] sau făcând parte din "dinamica sensului" [4], astfel modernizarea lexicului din domenii precum modã, economie, gastronomie a presupus împrumutarea unor cuvinte fie pentru a desemna ocupații sau operațiuni noi, fie pentru a înlocui alți termeni deja existenți. Odată intrate în limba română, neologismele au fost adaptate sistemului gramatical românesc sau au fost preluate ca în limba franceză (xenisme). Semnalând „raportul dintre vechimea cuvintelor în limba franceză şi a împrumuturilor în limba română", Florica Dimitrescu [5] distinge două categorii: 1) cuvintele de curând pătrunse în română din franceză pot avea la bază termeni mai vechi şi 2) cuvintele recente în română se explică prin termeni recenți şi în franceză.

Theodor Hristea [6] vorbeşte despre imprumuturi terminologice vechi şi imprumuturi terminologice neologice cu precizarea că acestea din urmă sunt numite astfel doar dacă au pătruns în limba română după a doua jumătate a secolului al XVIII-lea.

În ceea ce privește domeniul economic, înainte erau utilizate foarte multe cuvinte de origine slavă: dobândă, scump, de origine greacă/neogreacă: a economisi etc.; turcă: bacşiş, "numerar", maghiară: vamă, a cheltui; ucraineană: a socoti sau cu etimologie necunoscută precum ban sau leu, iar în limba română actuală observãm cã s-au înlocuit foarte mulți termeni cu neologisme preluate din limba franceză:

a chivernisi - a administra; mezat - licitație; leafă - salariu; vădea - scadență; zgârcit avar, adaptarea la limba română a neologismelor însemnând mai multe procese : 1) o modificare fonetică cerută de sistemul fonologic al limbii române, 2) o modificare semantică, atunci când relațiile dintre elementele limbii cereau reevaluări ale semnificației, 3) o modificare de statut morfologic pentru inscrierea în clasele flexionare româneşti [7].

De-a lungul timpului, cele mai multe schimbări au apărut la substantive, această parte de vorbire fiind foarte mobilă, astfel că în domeniul economic, dar și în cel gastronomic am împrumutat din limba franceză cuvinte precum :

bursier, antiinflationist, econometrie, petrodolar, presalariu, complex, butic, expertiză, patronat, acreditiv, active, arierate, anuitate, aperitiv, antreneu, cruditãți, sufleu, crochete, omletã, garniturã, piure, salatã, pateu, ecler, sirop, foie gras, tartar, biftec, carpaccio, însă avem şi substantive provenite din mai multe surse precum: recesiune, fr, engl, impact fr, engl, etc..

În categoria franțuzismelor sau peregrinismelor franceze, aşa cum le-a numit Florica Dimitrescu, regãsim următorii termeni din lexicul economic: butic, dar şi varianta butică, aceasta din urmă nemaiexistând în Dicționarul 
ortografic, ortoepic şi morfologic al limbii române, ediția a II-a, iar în ceea ce priveşte sensul, el însemna în limba franceză lieu d' etalage et de vente au detail [8], iar în limba română magazin în care se vând mărfuri de serie mică [9].

De precizat este faptul că în cazul acestui substantiv, ca şi în cazul cuvântului vizavi dupã pãtrunderea în limba românã, inițial, și-a pãstrat ortografia franțuzească, ca mai târziu scrierea să se realizeze conform principiului fonetic.

Un alt exemplu de termen care a intrat în limba românã, inițial pãstrându-și ortografia este bonjour, astãzi fiind întâlnit sub forma bonjur, dar și derivatul bonjurist care semnificã „epitet dat, pe la jumãtatea secolului al XIX-lea, tinerilor întorşi din strãinãtate, care o datã cu ideile progresiste introduceau și obiceiul cosmopolit de a se saluta cu bonjur în loc de bunã ziua." [10].

În ceea ce privește modalitățile de construire a unor cuvinte noi, existã douã posibilitãți:

„una populară care recurge aproape exclusiv la vechiul fond de prefixe şi sufixe şi una savantă care se adresează şi sufixelor greceşti, latineşti, romanice, şi mai rar, de altă origine, precum şi unui fond internațional de elemente de formare, de obicei cuvinte greceşti şi latineşti, prefixoide sau sufixoide " [11].

$\mathrm{Cu}$ ajutorul procedeului combinat numit calchiere, vocabularul se îmbogățeşte cu alte cuvinte, calcul fiind utilizat din necesitatea creării terminologiei ştiințifice încă din secolul al XVIII-lea [12].

Conform clasificării făcute de Theodor Hristea în lucrarea Sinteze de limba română, avem pe de o parte calc total sau integral care se realizează prin traducerea în totalitate a modelului din limba franceză (ex. conlucra $>$ fr. collaborer) şi semicalc sau calcul parțial (ex. deducere $>$ fr. deduire), iar pe de altă parte putem vorbi de calcul semantic şi calcul frazeologic.

In ceea ce priveşte calculul semantic, substantivul trust este unul dintre multiplele exemple, el semnificând în limba franceză enterprise qui fusionne des enterprises anciennnes, de maniere a reduire les prix et a produire d'advantage [13], în timp ce în limba română contemporană înseamnă asociație financiară sau economic importantã, care reuneşte mai multe societăți (comerciale, industriale etc.) sub o conducere unificată cu scopul de a asigura monopolul asupra unui produs sau a unui sector economic [14], acest sens fiind diferit de cel pe care îl avea în perioada de dinainte de Revoluția din '89 când prin acest termen se definea unitatea economică reprezentând o grupare de unități de producție sau desfacere a căror proprietate o deține şi o coordonează statul [15].

Spre deosebire de acestea, există şi neologisme în limbajul economic care au acelaşi sens în limba română[16] ca şi în limba franceză [17] : 
buget > fr. budget, care înseamnă bilanț al veniturilor şi cheltuielilor unui stat, ale unei întreprinderi, ale unei familii etc. pe o perioadă determinată. În țările europene, cuvântul buget a fost utilizat oficial la începutul secolului XIX-lea, iar în Franța s-a utilizat pentru prima dată în Legea bugetului de stat pe anul 1806. În Țările Române, apare pentru prima dată în Regulamentele Organice, care definesc sensul termenului "biudje" prin estimarea cheltuielilor anului viitor. După opinia specialiştilor, termenul buget îşi are originea în expresiile bouge şi bougette, care în limba franceză înseamnă punguță sau săculeț. [18]

Calculul semantic este şi el foarte bine reprezentat de sintagme precum :

taxa pe valoare adăugată $>$ taxe sur la valeur ajoutee, cont descoperit $>$ fr. compte decouvert, spațiu economic $>$ fr. espace economique, acoperirea metalică> fr. couverture metalique, acoperirea valorică $>$ fr. couverture valorique, monopoluri fiscale $>$ fr. monopoles fiscaux, monedă fără valoare integrală $>$ fr. monnaie sans valeur integrale etc.

Există cuvinte care au o dublă explicație, din punct de vedere formal prin limba latină, iar din punct de vedere semantic prin limba franceză, ceea ce înseamnă că sensul a fost preluat din limba franceză: efect, impozit etc. [19], dar există şi foarte mulți termeni care, deşi sunt de origine latină, au pătruns în limba română prin filiera limbii franceze:

salariu $>$ fr. salaire $>$ lat. salarium; tranzacție $>$ fr. tranzaction $>$ lat. tranzatio, -onis; comert $>$ fr. commerce > lat. commercium; numerar > fr. numéraire > lat. numerarius, iar altele au pătruns în acelaşi timp atât în limba română, cât şi în alte limbi: debit $>$ fr. debt $>$ lat. debitum, engl. debit, rus. Дебит, germ. debet, spaniolă débito; activ > fr. actif > lat. activus, rus. Aкmub, germ. aktiva, spaniolă activo; pasiv > fr. passif > lat. passivus, germ. passiv, engl. passive, spaniolă pasivo etc.

În ceea ce priveşte cuvintele provenite din limba franceză, academicienii Marius Sala şi Ion Coteanu sunt de părere că există o dihotomie, pe de o parte cuvinte considerate imprumuturi din francezăa, dar explicate şi ca formate pe teritoriul românesc, pe de altă parte cuvinte cu etimologie franceză şi alte etimologii[20].

Pentru cea de-a doua categorie, ei oferă ca exemplu cuvântul achizitor pe care unii lingvişti l-au explicat ca fiind un derivat românesc format din substantivul achiziție şi sufixul - tor (DEX, DN), iar Theodor Hristea [21] ca pe o creație românească din achizi(ție) prin substituție de sufix, însă termenul achizitor are un corespondent în franțuzescul acquisiteur folosit în Elveția.

Dacă limba română se caracterizează prin stabilirea unei relații între gen, terminații şi declinări, în limba franceză substantivele nu se clasifică în 
funcție de declinări, de aceea a fost nevoie de adaptarea neologismelor la sistemul limbii noastre, căci termenii la genul neutru primesc desinența uri după modelul românesc: trust-trusturi, capital-capitaluri etc.

În ceea ce priveşte locuțiunile, la unele observăm asemănări izbitoare între limba franceză şi limba română: ex. mot a mot, mettre au courant - a pune la curent, la altele observãm cã aceeași idee este exprimatã prin expresii diferite în cele douã limb ca în exemple precum:

râde ciob de oalã spartã care este în limba francezã c'est l'hopital qui se moque de la charité sau cine s-a fript cu ciorbã suflã și în iaurt care are ca și corespondent în francezã chat echaudé craint l'eau froide.

Totodatã, anumite personaje precum filfizon, skubilitic sau anumite toponime ca Strada Paris, Piața Charles de Gaulle, Strada Francezã etc. demonstreazã, încã o datã, cã limba francezã a avut și are o influență considerabilă asupra evoluției limbii și culturii române.

\section{NOTE:}

[1]. Adriana, Stoichițoiu-Ichim, Vocabularul limbii române actuale. Dinamicã, influențãa, creativitate. Editura All, București, 2001, p. 7.

[2]. Marius, Sala, 101 cuvinte moștenite, împrumutate și create, Editura Humanitas, București, 2010, p. 26.

[3]. Theodor, Hristea, Sinteze de limba română, Editura Didactică şi Pedagogică, Bucureşti, 1981, p. 100.

[4]. Adriana, Stoichițoiu-Ichim, op. cit., p. 12.

[5].Florica, Dimitrescu, Dinamica lexicului românesc, Editura Clusium Logos, București, 1995, p. 242-243.

[6]. Ibidem, p. 40.

[7]. Ioan, Oprea \& Rodica, Nagy, Istoria limbii române literare. Epoca modernă, Editura Universității Suceava, 2002, p. 163.

[8]. Larousse de poche, Librairie Larousse, Paris, p. 45.

[9]. Gabriel, Angelescu \& Emilia, Mareş, Dicționarul fundamental al limbii române explicativ, morfologic, ortografic şi ortoepic, Editura Aula, Braşov, 2008, p. 161.

[10]. https://dexonline.ro/definitie/bonjur;

[11]. Ion, Coteanu, \& Marius, Sala, Etimologia şi limba română, Editura Academiei Republicii Socialiste România, Bucureşti, p. 75.

[12]. N. A, Ursu, Formarea terminologiei ştiințifice româneşti, Editura Ştiințifică şi Pedagogică, Bucureşti, 1962, p. 117-118.

[13]. Larousse de poche, p. 45.

[14]. Gabriel, Angelescu \& Emilia, Mareş, op. cit., p. 161. 
[15]. ***, Dicționarul explicativ al limbii române, Academia Română, Institutul de Lingvistică „Iorgu Iordan“, Editura Academiei Române, Bucureşti, 1975, p. 1261.

[16]. Gabriel, Angelescu \& Emilia, Mareş, op. cit., p. 156.

[17]. Lydia, Ciucă, Dicționar francez-român, Editura Corint, Bucureşti, 2007, p. 96;

[18]. Elena, Deju, Preocupări, Editura Printex, Focşani, 2014, p. 13.

[19]. Theodor, Hristea, op. cit., p. 44-45.

[20]. Sala, Coteanu, op.cit. p. 148.

[21]. Teodor, Hristea, „Limba română“ XXVIII, București, 1979, p. 459.

\section{BIBLIOGRAFIE SELECTIVĂ:}

Angelescu, Gabriel, Mareş, Emilia, Dicționarul fundamental al limbii române explicativ, morfologic, ortografic şi ortoepic, Editura Aula, Braşov, 2008.

Bidu-Vrănceanu, Angela, Lexicul specializat în mişcare de la dicționare la texte, Editura Universitătii din Bucureşti, 2007.

Cazacu Boris, Rosetti, Alexandru, Istoria limbii române literare, (vol I), Editura Minerva, Bucureşti, 1971.

Călăraşu, Cristina, Dicționar de terminologie a profesiunilor actuale, Editura Universității din Bucureşti, 2004.

Cicile, Jean-Michel, Terminologie bancaire, financiere \& economique, Banque Editeur, Paris, 1998.

Ciorănescu, Alexandru, Dicționarul etimologic al limbii române, Editura Saeculum I.O, Bucureşti, 2005.

Ciucă, Lydia, Dicționar francez-român, Editura Corint, Bucureşti, 2007.

Coteanu, Ion \& Sala, Marius, Etimologia şi limba română, Editura Academiei Republicii Socialiste România, Bucureşti, 1987.

Coteanu, Ion, Formarea cuvintelor în limba română. Derivarea. Compunerea. Conversiunea, editat de Narcisa Forăscu, Angela Bidu-Vrânceanu, Editura Universității din Bucureşti, 2007.

***, Dicționarul explicatio al limbii române, Academia Română, Institutul de Lingvistică „Iorgu Iordan“, Editura Academiei Române, Bucureşti, 1975.

***, Dicționar poliglot economic, de comerț exterior şi turism, Editura Garamond, Bucureşti, 2003.

Dimitrescu, Florica, Dinamica lexicului românesc, Editura Clusium Logos, Bucureşti, 1995.

Dimitrescu, Florica, Dicționar de cuvinte recente, Editura Albatros, Bucureşti, 1982.

Dubois, Jean \& Mitterand, Henri \& Dauzat, Albert, Dictionnaire d'étymologie, Larousse, Paris, 2001.

***, Formarea cuvintelor în limba română, (vol. I - Compunerea), Editura Academiei Române, Bucureşti, 1970.

Hristea, Theodor, Sinteze de limba română, Editura Didactică şi Pedagogică, Bucureşti, 1981. 
Iacob, Niculina, Limbajul biblic românesc, Editura Universității "Ştefan cel Mare“, Suceava, 2001.

Stoichițoiu-Ichim, Adriana, Vocabularul limbii române actuale. Dinamică, influență, creativitate, Editura All, Bucureşti, 2001.

Ionescu, C. Lucian, Fundamentele profesiunii bancare. Băncile şi operațiunile bancare, Institutul Bancar Român, Editura Economică, 1996.

Giugu, Aurel Ioan \& Ungurean, Pavel Vasile \& Duma, Sebastian Florin, Mic lexicon financiar-bancar şi bursier, Editura Didactică şi Pedagogică, Bucureşti, 2009.

Miroiu, Mihai, Dicționar de termeni economici, financiar-bancari şi de bursă - englez, francez, român, Editura Andreescu, Alexandria, 1992.

Negreanu, Aristița, Dicționar de expresii francez-român, Editura All, Bucureşti, 2002;

Sala, Marius, 101 cuvinte moştenite, imprumutate şi create, Editura Humanitas, Bucureşti, 2010.

Savin, Vasile \& Savin, Cristina-Anca, Dictionar român-francez administrativ, comercial, economic, financiar - bancar, juridic, Editura Dacia Educational, Cluj Napoca, 2002.

Sherif, Hasdem Mostafa \& Serouchmi, Ahmed, La monnaie electronique. Systeme de paiement securise, Editura Eyrolles, Paris, 2000.

Treps, Marie, Les mots migrateurs. Les tribulations du français en Europe, Éditions du Seuil, Paris, 2009.

Troacă, Victor, Lexicon bancar, Editura Tribuna Economică, Bucureşti, 2001.

Ursu, N.A, Formarea terminologiei ştiințifice româneşti, Editura Ştiințifică şi Pedagogică, Bucureşti, 1962.

Véronique, Alexandre, Léxique de termes économiques - français, anglais, chinois, Edition Economique, Paris, 2001.

Revista Finanțe, bănci, asigurări, nr.1/2002, Editura Tribuna Economică.

Revista Preocupãri, Editura Printex, Focșani, 2014.

\section{Les aspects de l'influence de la langue française sur la langue roumaine}

Résumé: L'influence de la langue française sur la langue roumaine est liée au contexte politique, les premiers mots d'origines françaises entrant dans la langue à partir du XVIIIème siècle par le biais des grecques qui ont vécu en Moldavie et Valachie ou au moment de l'apparition des migrants français. Dans la première moitié du XIXème siècle, les mots français sont introduits dans la langue roumaine en général avec l'aide des jeunes roumains qui ont fait les études en Paris, et dans la deuxième moitié du XIXème siècle cette influence acerbe est ironisée par certains écrivains roumains. Au XXème siècle, l'influence de la langue française est encore présente dans plusieurs domaines comme la cuisine, la mode, l'économie et dans le XXème siècle on peut observer que dans le domaine culinaire on emprunte encore beaucoup de mots français. Compte tenu des aspects mentionnées précédemment, dans cet article on propose une description de l'influence de langue française sur la langue roumaine dans les différents 
domaines d'activités, la recherche de ces faits linguistiques viens compléter les études déjà existantes au niveau national, le but étant le suivi, la présentation et l'analyse des conséquences au plan linguistique apparaitrais dans notre langue comme une conséquence du contact qu'a eu cette dernière, toute au long de son évolution, avec la langue française. Apres un bref aperçu de l'apparition dans le vocabulaire de la langue roumaine aux thermes d'origine française, on se concentre sur l'évolution du mot bonjour, sur ce qui Theodor Hristea nomme „împrumuturi terminologice vechi“ (emprunts terminologiques vieux) et "împrumuturi terminologice neologice“ (emprunts terminologiques néologiques), sous l'analyse de mots du domaine culinaire, économique, ou de la mode, mais aussi sur le fait qu'un mot français a donné dans la langue roumaine deux mots.

Mots cles: l'influence, linguistiques, vocabulaire, française, roumaine. 